\title{
POSSIBILIDADES DE UTILIZAÇÃO DO SOFTWARE GRAFEQ NA RELAÇÃO DA MATEMÁTICA E ARTE NO ENSINO MÉDIO
}

\author{
Juliane Carla Berlanda, Universidade Federal de Santa Maria \\ Débora da Silva Soares, Universidade Federal do Rio Grande do Sul
}

\begin{abstract}
Resumo
Esse relato apresenta uma experiência didática que realizamos com estudantes do segundo ano do ensino médio, com principal objetivo de promover uma reflexão acerca das possibilidades e limitações da prática realizada. A atividade que propomos consiste em relacionar a matemática e a arte juntamente com a utilização de tecnologias informáticas, a partir da construção de réplicas de obras de arte do artista brasileiro Geraldo de Barros com o uso do software GrafEq. Dentre as possibilidades da proposta, identificou-se que foi proporcionado aos estudantes a obtenção de novos conhecimentos em relação à matemática e à arte, sendo que reconhecemos como fundamental para o desenvolvimento da mesma a utilização de recurso tecnológico. Com relação às limitações da proposta, será importante pensar em estratégias que possam instigar a todos os alunos a participarem da tarefa.
\end{abstract}

Palavras-chave: matemática e arte; tecnologias; software grafeq.

\section{OPPORTUNITIES OF GRAFEQ SOFTWARE USE IN RESPECT OF MATHEMATICS AND ART IN SECONDARY EDUCATION}

\begin{abstract}
Abstact
This report presents an educational experience that has been conducted with students of the second year of high school with the main purpose to promote a reflection on the possibilities and limitations of the accomplished practice. The activity that has been proposed is to relate mathematics and art along with the use of information technologies, from the construction of replicas of the Brazilian artist works Geraldo de Barros using the GrafEq software. Among the possibilities of the proposal, it was identified that students could get new knowledge regarding mathematics and art, and the use of technological resources have been recognized as fundamental to its development. In relation to the limitations of the proposal, it will be important to think about strategies that can instigate all students to participate in the task.
\end{abstract}

Keywords: mathematics and art; technologies; GrafEq software.

\section{Introdução}

Este relato de experiência apresenta a análise de uma prática desenvolvida pela autora no âmbito do curso de especialização Matemática, Mídias Digitais e Didática, oferecido pela Universidade Federal do Rio Grande do Sul (UFRGS). O objetivo da prática era apresentar a importância e a relação entre a matemática e a arte no processo de ensino e aprendizagem, mediado pelo software GrafEq e por um site que contém material interativo, o qual embasou o desenvolvimento de uma das disciplinas oferecidas na especialização ${ }^{1}$. Este material serviu como estímulo e inspiração para a elaboração da prática, a qual propôs aos estudantes a construção de réplicas de obras de arte do artista brasileiro Geraldo de Barros com o software GrafEq. Outro objetivo da prática era relacionar os conteúdos de equações de reta, inequações e intervalos numéricos com suas representações geométricas. A proposta foi realizada na cidade de Erechim - RS em uma escola da rede pública estadual, no turno da manhã, com estudantes de uma turma do $2^{\circ}$ ano do ensino médio.

De acordo com Maltempi (2008), cada vez mais as escolas recebem alunos usuários de tecnologias, os quais pressionam pelo seu uso na educação ao levarem-nas para a sala de aula ou ao relacionarem as atividades realizadas com a possibilidade de

\footnotetext{
${ }^{1}$ http://www.ufrgs.br/espmat/
} 
serem elaboradas com o apoio desses recursos. Aliar os recursos informáticos ao ensino de matemática pode ser uma forma de torná-lo mais crítico, dinâmico e significativo, tornando o estudante mais ativo na construção do próprio conhecimento, tornando as aulas mais atrativas e motivadoras.

Além disso, a matemática e a arte relacionadas possibilitam que o educando desenvolva capacidade de imaginar, criar, experimentar, analisar, representar e argumentar, fazendo com que o professor utilize diferentes recursos para a criação de situações de aprendizagem desafiadoras.

O software Grafeq foi escolhido pelo fato de seus comandos serem fáceis de serem utilizados facilitando a exploração de forma dinâmica dos conceitos e propriedades de matemática, para a construção de réplicas das obras de arte de Geraldo de Barros, pois reúne conceitos de geometria, álgebra e gráficos em um único ambiente. Como ressaltam Gravina e Basso (2012, p.113) "Nas construções com o GrafEq são necessários os conceitos de função, equação, inequação e suas representações gráficas, [...]". Além disso, é gratuito, fácil de instalar e está disponível para todos.

Da mesma forma, a possibilidade de visualizar e manipular as ideias matemáticas é apontada por Kawasaki (2008) como uma das principais vantagens ao incorporar as tecnologias computacionais nas aulas de matemática, tendo em vista que a utilização de um software matemático adequado possibilita a visualização dinâmica e interativa de um objeto matemático virtual que pode ser alterado, deslocado e rotacionado, trabalhos pedagógicos que antes eram inviáveis por limitações de recursos físicos, custo e tempo.

Assim, a utilização de recursos informáticos nas aulas de matemática não assume a ideia de uma matemática pronta a ser ensinada, mas sim de se fazer matemática. Utilizar esses recursos, porém, implica uma reflexão, discussão e organização do ambiente de aprendizagem, pois o professor deve estar preparado para discutir com seus alunos todos os conceitos e propriedades matemáticas envolvidas na construção das réplicas de figuras de arte. Foi com base nessas reflexões que a prática foi planejada e aplicada. Na sequência do artigo, a prática será apresentada com detalhes e uma reflexão acerca de suas possibilidades e limitações será desenvolvida.

\section{Recursos Tecnológicos e Matemática e Arte}

Nos dias atuais, o avanço tecnológico tem ocorrido de maneira muito rápida, influenciando direta ou indiretamente a vida das pessoas. As gerações atuais, já inseridas nessa cultura tecnológica, lidam facilmente com esses avanços. Borba e Penteado (2007) descrevem o estudo de Levy (1993), enfatizando que:

[...]a história da humanidade está sempre impregnada de mídias, e que devemos de fato nos preocupar com as transformações do conhecimento nesse momento em que uma nova mídia, no caso a informática, está se tornando cada vez mais presente em nosso cotidiano.

Então é essencial atualizar a forma de trabalhar em sala de aula, já que esses meios tecnológicos estão aí para nos auxiliar. Nesse sentido, Souza (2013) defende que o uso de softwares matemáticos contribui para a visualização e verificação de propriedades e auxiliam na resolução de problemas, uma vez que apenas com lápis, papel e instrumentos de medição e desenho, algumas construções e efeitos seriam pouco viáveis ou impossíveis de serem realizados. Os Parâmetros Curriculares Nacionais (PCN) de Matemática também recomendam que o ensino de Matemática aproveite ao máximo os recursos tecnológicos, tanto pela sua receptividade social como para melhorar a linguagem expressiva e comunicativa dos alunos (BRASIL, 1998).

Segundo Borba e Penteado (2007) o uso de tecnologias no ensino de Matemática pode demandar que o professor deixe sua zona de conforto e se movimente 
em uma zona de risco. Isto porque algumas situações inesperadas podem ocorrer, dentre elas: perda do controle devido a problemas técnicos, perguntas imprevisíveis dos estudantes, não estar familiarizado com o programa escolhido. Além disso, o professor necessita de uma atualização constante sobre essa área, pois não existe uma forma de aprender a utilizar tecnologias de uma vez só, uma vez que as tecnologias da informação estão em transformação contínua. É impossível permanecer em uma zona de risco sem se movimentar em busca de novos conhecimentos.

Para o desenvolvimento da prática escolhemos o software GrafEq, conforme mencionamos na Introdução deste artigo, pois com o seu dinamismo pode-se reproduzir paisagens, mosaicos, réplicas de obras de arte, entre outros. Isso se deve ao fato de que "a sua interface de trabalho é bastante simples e tem recursos de cores que produzem efeitos interessantes" (GRAVINA; BASSO, 2012, p.23). Além de todas as características citadas acima, a utilização deste software no ensino de Matemática pode contribuir para que o estudante tenha uma visualização mais clara e compreensível das propriedades matemáticas.

Já a utilização de Materiais Virtuais Interativos pode contribuir para a compreensão de conteúdos matemáticos e para a interação entre estudantes e professor e, como consequência no processo de ensino aprendizagem, pode despertar maior interesse dos estudantes por esta disciplina tão fascinante. Segundo Gravina e Basso (2012, p.12), "Nossas rotinas na sala de aula também deveriam incorporar, cada vez mais, as tecnologias, pois elas também influem nas nossas formas de pensar, de aprender, de produzir."

Pensando no uso das tecnologias informáticas em sala de aula e no processo de ensino aprendizagem da matemática, elaborou-se uma proposta cujo objetivo é que os estudantes reproduzam uma réplica de obra de arte do artista brasileiro Geraldo de Barros escolhida por eles mesmos, utilizando o software GrafEq, relacionando os conteúdos matemáticos como reta, inequações e intervalos numéricos, para $\mathrm{o}$ desenvolvimento do trabalho ${ }^{2}$. Nesse sentido, o objetivo principal da proposta era que os estudantes percebessem a Geometria e a Álgebra nas obras de arte, os conteúdos matemáticos envolvidos, e associassem-nos às construções geométricas, com o auxílio do software Grafeq.

Com relação à arte e à matemática, segundo Zaleski Filho (2013), essas duas áreas surgiram juntas, pois desde o período pré-histórico os homens já categorizavam, dimensionavam e demonstravam a realidade que estavam inseridos por meio de pinturas rupestres, ossos entalhados e outras maneiras, representando a ligação entre a arte e a matemática, a partir da representação do mundo real.

A partir deste período pré-histórico, as gerações foram se desenvolvendo e as maneiras de representação foram evoluindo e adequadas de acordo com as necessidades de sobrevivência. Ao longo do tempo, desde a Filosofia Grega até a atualidade, percebeu-se que a arte e a matemática se distanciaram e, infelizmente, isso também ocorreu nas escolas, pois, como ressalta Zaleski Filho (2013), o ensino da arte se tornou componente curricular a parte das outras disciplinas. Porém, de acordo com Zaleski Filho (2013), a reaproximação entre matemática e a arte só tem a enriquecer o processo

\footnotetext{
${ }^{2}$ Esta proposta foi inspirada no trabalho proposto em uma das disciplinas do Curso de Especialização. Disciplina: Mídias Digitais na Educação Matemática II; Teoria e Prática Pedagógica III Módulo II: A Arte e a Matemática. Disponível em: 〈https://moodle.ufrgs.br/course/view.php?id=27180〉
} 
de ensino e aprendizagem, pois a contextualização do saber deve contemplar uma posição de ressalto nos programas escolares.

\section{Desenvolvimento da prática}

A prática foi desenvolvida em quatro períodos de 45 (quarenta e cinco) minutos cada, como mencionado anteriormente, com estudantes do $2^{\circ}$ ano do ensino médio de uma escola pública estadual, com 29 alunos. As atividades foram desenvolvidas em sala de aula, em duplas ou trios de alunos, e os mesmos trouxeram seus notebooks para a escola.

A turma em que foi desenvolvida esta prática é interessada e dedicada, estão sempre dispostos a aprender coisas novas e a novos desafios. Não apresentam dificuldades de aprendizagem, exceto alguns poucos alunos. Porém, às vezes apresentam dificuldades em relacionar determinado conteúdo trabalhado em sala de aula com uma situação do cotidiano, ou seja, não conseguem notar que certa definição matemática pode ser utilizada para resolver determinada situação. Não apresentam problemas de indisciplina, mas como são em bastante número, são um pouco agitados. Sendo assim, a relação entre eles é de amizade e companheirismo.

Pensando no aprendizado da autora no curso de especialização, no potencial da utilização de recurso tecnológico nas aulas, no perfil da turma e no objetivo, já reportado, foram elaborados alguns objetivos específicos para fundamentar essa prática, bem como uma sequência de atividades. Primeiramente, seria necessário que os estudantes tivessem familiaridade em trabalhar com o software escolhido, o Grafeq, pois todas as atividades seriam desenvolvidas com esse programa. Além disso, os estudantes seriam instigados a relacionar os conceitos e propriedades matemáticos, reta, inequações, intervalos numéricos e quadriláteros, com suas respectivas representações geométricas, para então conseguir relacionar e perceber a ligação dos conteúdos matemáticos com as obras de arte do artista Geraldo de Barros.

A partir disso, o plano de ações baseou-se, primeiramente, em uma retomada dos conteúdos necessários para construção das réplicas de obras de arte. Os conceitos matemáticos revisados foram: reta, inequações, intervalos numéricos e quadriláteros, assim como suas respectivas representações geométricas construídas no software GrafEq. Essa revisão foi necessária e fundamental, pois esses conteúdos que seriam necessários para a construção das releituras das obras de arte, foram estudados pelos alunos no ano anterior. Essas explicações foram embasadas no $\operatorname{site}^{3}$ da disciplina da especialização, "Mídias Digitais II", utilizado pela primeira autora enquanto aluna do curso de especialização. Optou-se pela retomada dos conceitos matemáticos com base na apresentação do site aos alunos utilizando o projetor multimídia, escolha que propiciou uma economia de tempo em comparação com o uso de quadro e giz.

Para auxiliar na familiarização dos estudantes com o software, a professora construiu com eles duas réplicas de obras de Geraldo de Barros (Fig.1; Fig.2), para que fossem esclarecidas dúvidas referentes ao software e em relação às definições matemáticas utilizadas para a composição da obra de arte. Algumas curiosidades referentes às obras foram apresentadas aos estudantes, pois é interessante que eles conheçam a arte brasileira.

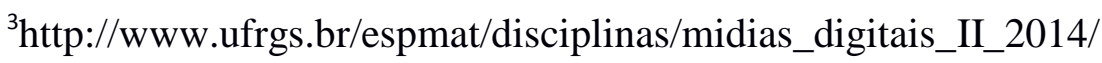


Figura 1 - Obra de arte de Geraldo de Barros

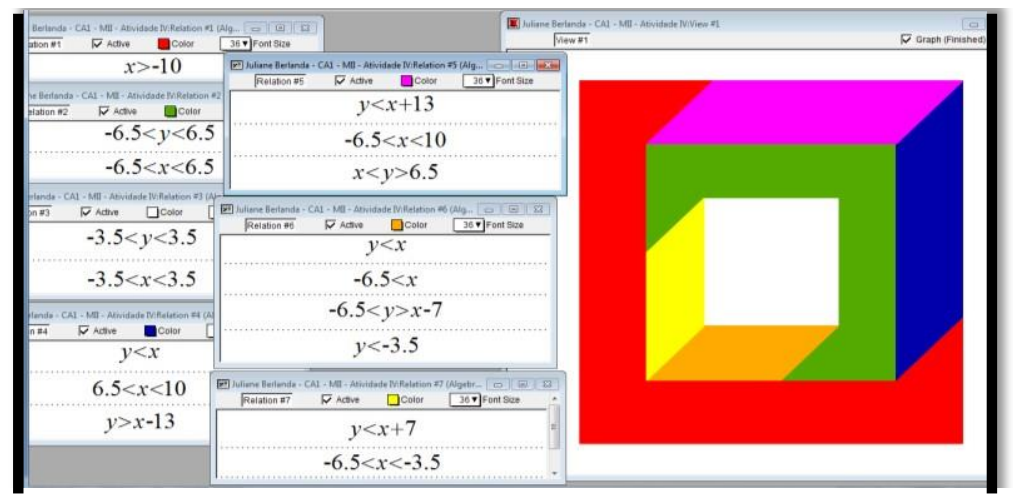

Fonte: Produção própria do autor.

Figura 2 - Réplica da obra de arte de Geraldo de Barros

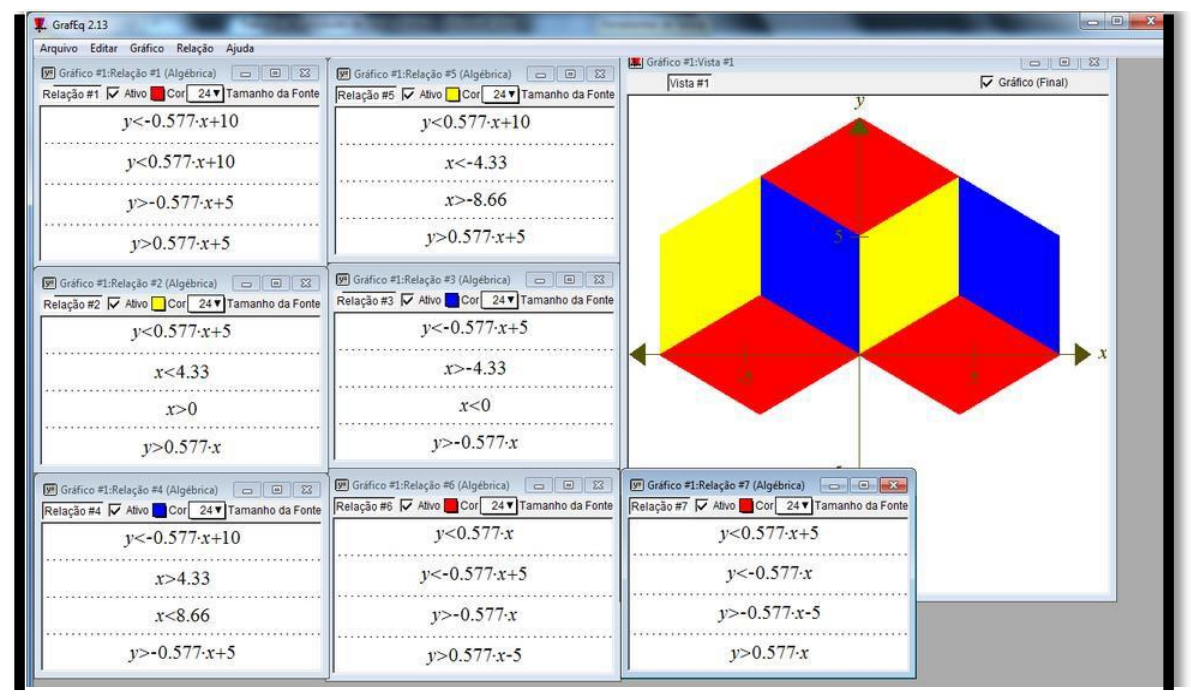

Fonte: http://www.ufrgs.br/espmat/disciplinas/midias_digitais_II_2014/

$\mathrm{Na}$ sequência, os estudantes realizaram uma busca na internet sobre as obras referentes a esse artista brasileiro para escolha de pelo menos uma para a construção da sua réplica de arte. A liberdade de pesquisa sobre o artista e sobre suas obras, permitiu aos estudantes maior autonomia na realização da atividade.

\section{Resultados}

Buscando propiciar a compreensão da proposta pedagógica desenvolvida utilizaremos a Teoria dos Registros de Representação Semiótica de Raymond Duval. Segundo essa teoria, a utilização de diferentes registros de representação associados a um mesmo objeto matemático e a coordenação conveniente entre estes registros mostra uma possibilidade do estudante assimilar o objeto matemático em sua totalidade. Os objetos matemáticos são ideias, relações, propriedades e conceitos que podem demonstrar situações diferentes por meio de representações simbólicas. Nesse sentido, deve-se considerar as diferentes formas de representação e registro de um mesmo objeto matemático.

Segundo Vertuan (2007), na teoria de Duval os registros são feitos na linguagem usual, na linguagem numérica, na linguagem algébrica e na linguagem gráfica. As mudanças de representação semiótica são chamadas de transformações, sendo que 
existem dois tipos delas: transformação de tratamento e transformação de conversão. A teoria de Duval diz que a compreensão em matemática se dá quando o estudante conseguiu atingir mais de um registro de mesmo objeto matemático. Ou seja, uma aprendizagem acontece quando se conquista a capacidade de mudar de registro e de diferenciar um objeto de sua representação. Levando em conta essas considerações, esperava-se promover ao aluno o contato com, pelo menos, dois registros de equações e inequações simultaneamente, a saber, o registro algébrico e o registro gráfico.

A apresentação do software GrafEq foi tranquila, os estudantes acharam o programa bem acessível, fácil de manipular e pôde-se observar que durante as atividades eles não sentiram dificuldades, pois em nenhum momento a professora foi solicitada para tirar dúvidas em relação ao programa, pelo contrário eles exploraram bastante o software e descobriam sozinhos o que procuravam.

Em seguida, com o auxílio do material disponível no site do curso Matemática, Mídias Digitais e Didática e com o auxílio do projetor multimídia, a professora retomou os conceitos e propriedades matemáticas, equação, inequação, intervalos numéricos e quadriláteros e suas respectivas representações geométricas no software, onde os estudantes, juntamente com a professora, digitavam as relações no software Grafeq para melhor entendimento, já que, posteriormente seriam necessários para a construção das réplicas de obras de arte. Essa revisão de conceitos, foi fundamental para relembrar aspectos que os estudantes não lembravam mais, bem como conceitos que não estavam tão claros, como por exemplo, a inclinação de uma reta, também, como construir um quadrilátero a partir de retas e intervalos numéricos.

$\mathrm{Na}$ última etapa do trabalho, na criação da réplica escolhida por eles mesmos, observou-se a facilidade com que os estudantes realizaram a réplica escolhida, bem como as mesmas ficaram extremamente semelhantes (Fig. 5 a 8); foi surpreendente tal empolgação, agilidade e raciocínio que os mesmos tiveram durante toda essa etapa.

Muito interessante mencionar que para a construção de quadrados ou retângulos, quando as obras de arte apresentavam esses quadriláteros, não houve nenhuma dificuldade, os estudantes souberam de forma bem ágil fazer essas construções (Fig. 3, 4, 7 e 8). Apenas na construção de trapézios, triângulos ou quando tinham de criar restrições, intervalos numéricos para as construções (Fig. n 4,6,7 e 8), foi possível verificar que os mesmos sentiram um pouco mais de dificuldade.

Durante essas construções era possível escutar as vibrações quando os estudantes conseguiam acertar alguma relação e quando conseguiam concluir sua réplica, as expectativas deles quanto ao planejamento das leis matemáticas para verificação se estava certo ou não.

Muitas discussões entre eles também surgiram, boa parte das construções os estudantes, de tão envolvidos que estavam, discutiam em um tom de voz elevado por não concordarem com a relação que o colega colocou, ou por não ter dado certo algo, mas tudo em prol de acertar a relação matemática com a representação geométrica para que realmente ficasse igual à da obra original.

Outro aspecto relevante, que não pode ser esquecido, foi um grupo composto por três meninas no qual elas optaram por ter como auxílio o papel. Elas desenharam o plano cartesiano e a partir da construção das partes da réplica escolhida, primeiramente no papel para depois passar as informações obtidas para o software.

Dois grupos de alunos, apresentaram mais facilidade que os outros conseguindo realizar quatro réplicas e outro, três réplicas de obras de artes do artista aqui pesquisado, iniciando em aula com término em casa.

Nesse sentido, observou-se que a maioria dos estudantes conseguiu trabalhar e coordenar mais de um registro do mesmo objeto matemático, analisando a equação, 
inequação ou intervalo numérico com a representação gráfica proporcionada pelo software GrafEq, como mostram as figuras abaixo. Conforme comentado anteriormente, a teoria de registros de representação semiótica indica a coordenação de diferentes registros como fundamental à aprendizagem do conceito matemático.

Também é importantíssimo lembrar que muitos estudantes além de terem participado em aula, realizado o solicitado, não se sentiram satisfeitos e fora do horário da aula pesquisaram por mais artistas brasileiros construindo réplicas das obras de Piet Mondrian, pois também acharam uma obra bastante interessante. Outros pesquisaram sobre o software e encontraram algumas sugestões de construção, que também o fizeram. Quanto a relação entre as áreas da arte e da matemática observou-se que a maioria dos estudantes ficou extremamente surpresos com tal casamento entre essas duas áreas.

Diante da repercussão positiva dessa atividade desenvolvida, as réplicas construídas e a obra original foram impressas, como um comparativo, e exposto em um mural da escola, para que outros estudantes pudessem visualizar a beleza dessas construções, aprender sobre a arte brasileira e, principalmente, perceber a relação entre a matemática e arte com recurso tecnológico.

Segue abaixo algumas construções feitas pelos estudantes, bem como a obra original de Geraldo de Barros:

Figura 3 - Réplica da obra construída pelos estudantes / Obra original

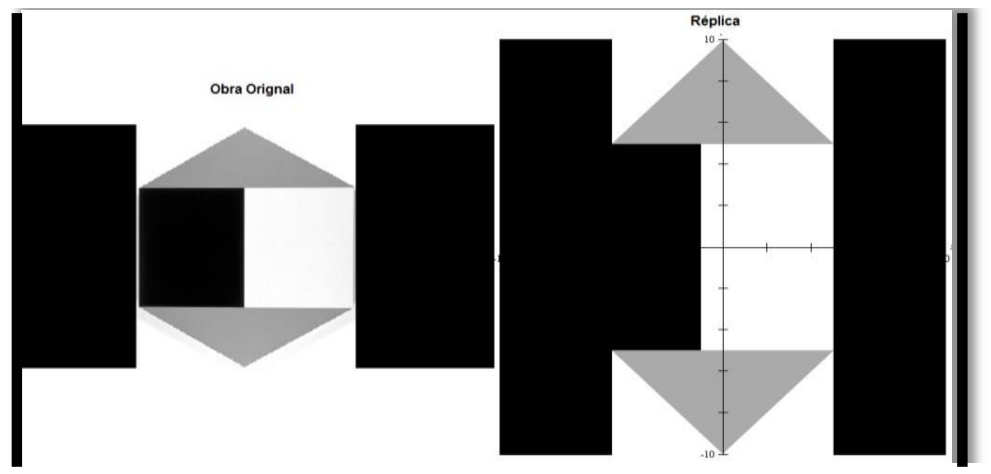

Fonte: Dados da pesquisa

Figura 4 - Relações matemáticas utilizadas para construção da réplica

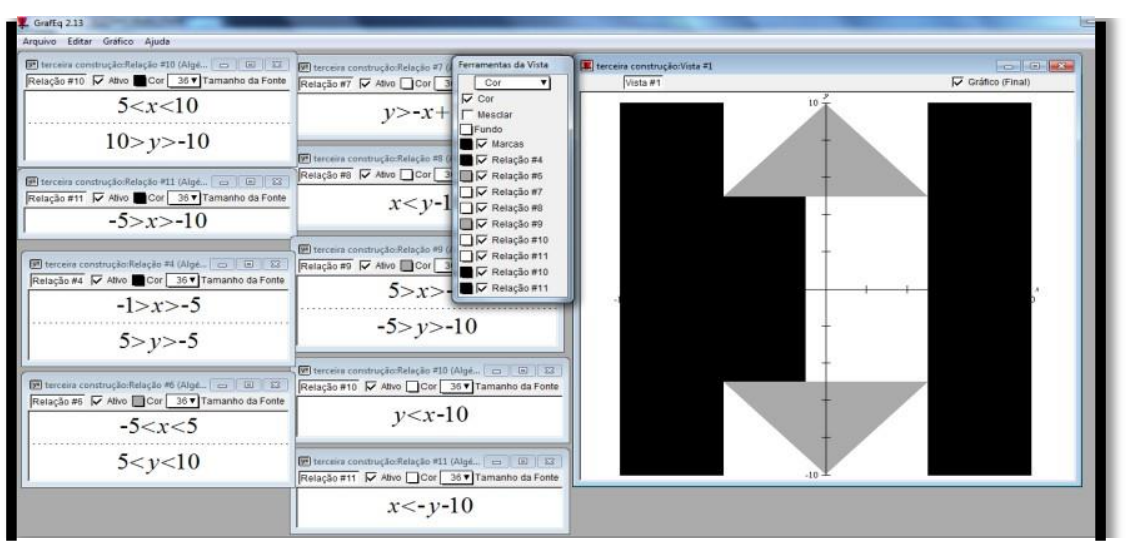

Fonte: Dados da pesquisa 
Figura 5 - Réplica da obra construída pelos estudantes / Obra original
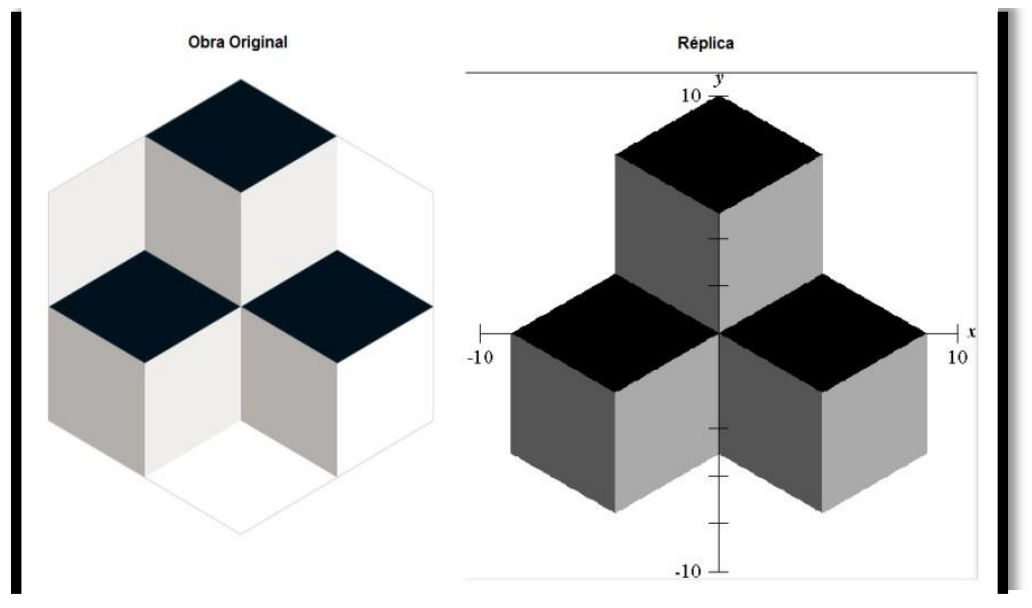

Fonte: Dados da pesquisa

Figura 6 - Relações matemáticas utilizadas para construção da réplica

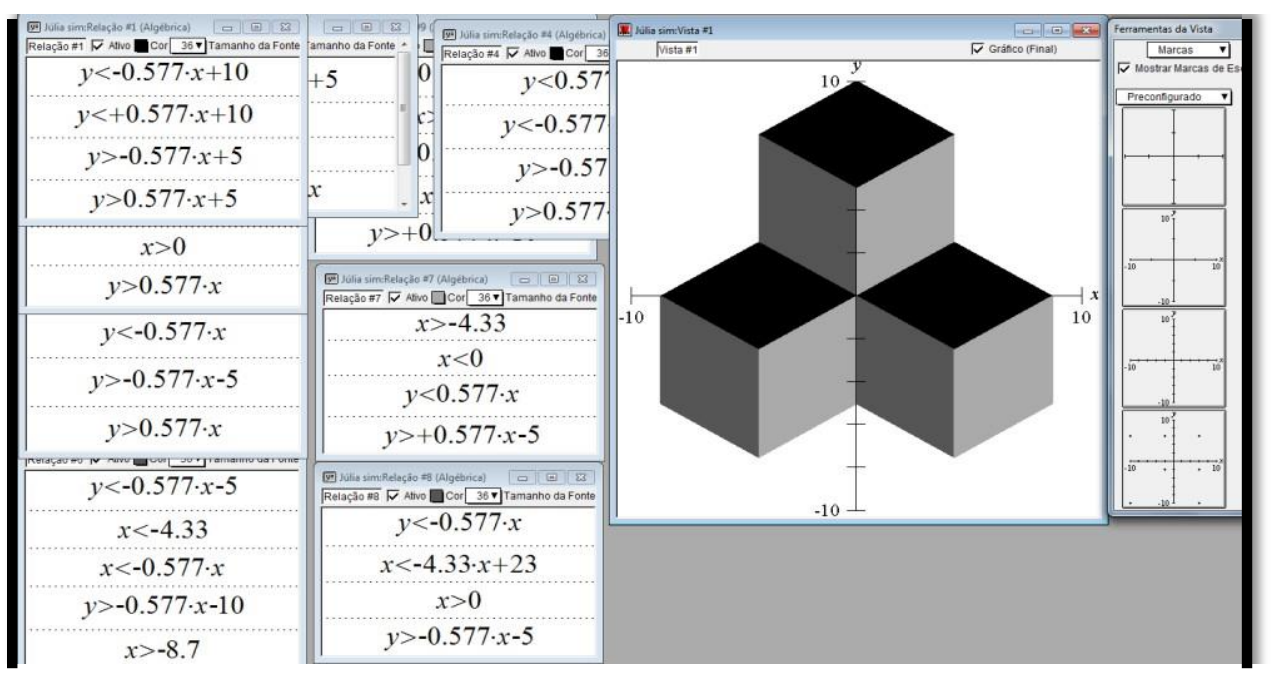

Fonte: Dados da pesquisa

Figura 7 - Réplica da obra construída pelos estudantes / Obra original e Relações matemáticas utilizadas para construção da réplica
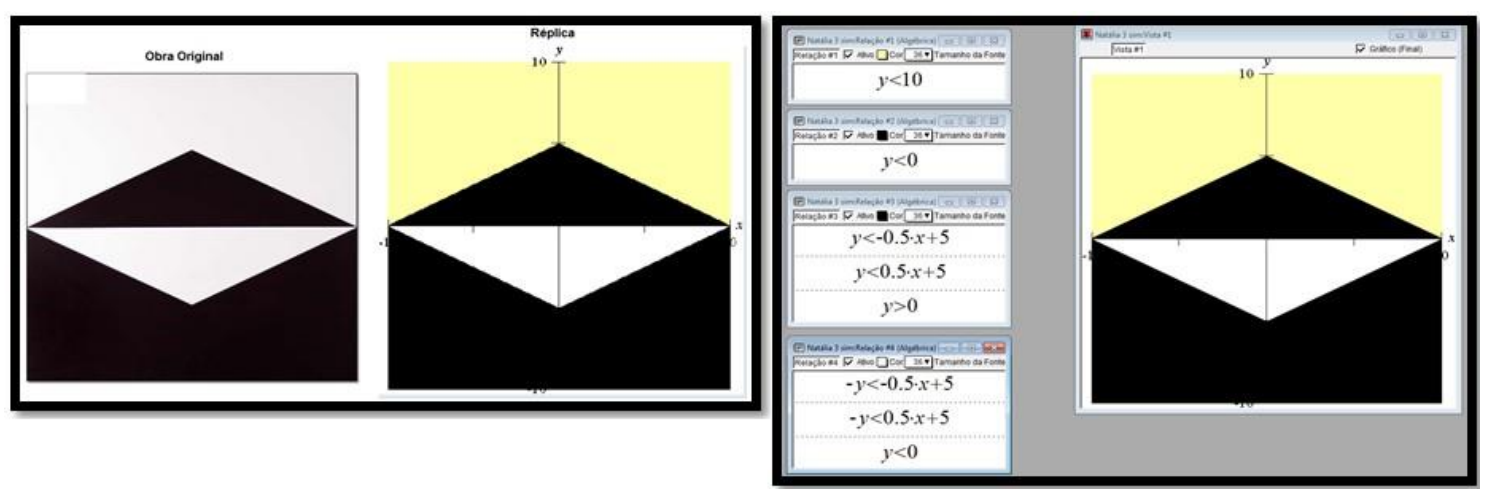

Fonte: Dados da pesquisa 
Figura 8 - Réplica da obra construída pelos estudantes / Obra original e Relações matemáticas utilizadas para construção da réplica
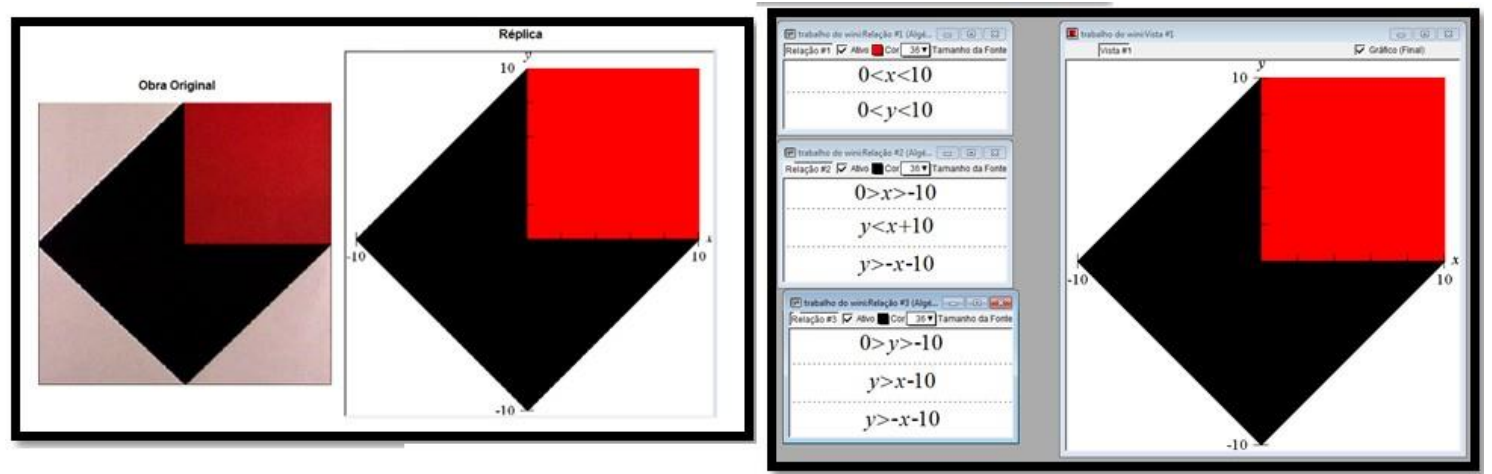

Fonte: Dados da pesquisa

\section{Considerações Finais}

A experiência exigiu a busca de ferramentas que em geral não são utilizadas em sala de aula, a saber a utilização de recurso tecnológico, o software GrafEq e a relação da matemática com outra área do conhecimento, a arte. Essas ferramentas ampliam e reorganizam a possibilidade do campo de ação dos estudantes, pois foi partir desses instrumentos que os mesmos puderam construir seu conhecimento. Isso se deve ao fato das atividades terem sido planejadas centradas nesses instrumentos.

$\mathrm{O}$ aspecto histórico sobre a arte e a matemática mostrou que em muitos momentos no decorrer dos tempos, desde a era primitiva até a atualidade, essas duas áreas do conhecimento se distanciaram, porém, elas aparecem totalmente ligadas desde os primeiros registros feitos. Ainda hoje, os parâmetros curriculares nacionais não indicam o trabalho em conjunto entre ambas. Essas reflexões poderiam estar presentes no desenvolvimento dos educadores para que esses, em exercício, possam contribuir ao processo de ensino aprendizagem da Matemática e da Arte praticada em sala de aula.

Ao refletir sobre a prática, percebemos que houve sucesso na estratégia de ensino, pois tanto o objetivo central como os objetivos específicos para realização dessa prática foram alcançados. De fato, os estudantes obtiveram um conhecimento novo, aprendendo que a relação entre a matemática e a arte existe, relacionando os conceitos e propriedades matemáticas com as representações geométricas e utilizaram com facilidade o software GrafEq. Além disso, com base na Teoria dos Registros de Representação Semiótica proposta por Duval, foi possível evidenciar o trabalho simultâneo com diferentes registros de equações e inequações.

Uma possível limitação desta prática foi o fato de que um número mínimo de estudantes, por não possuírem um notebook exclusivo para si, acharam que não deveriam participar nem colaborar para a construção da réplica, atrapalhando os demais alunos. A prática foi proposta para ser desenvolvida em pequenos grupos, de modo que os notebooks eram compartilhados. Para uma próxima edição da prática, será importante pensar em estratégias que possam instigar a todos os alunos a participarem da tarefa.

A utilização do software GrafEq, como recurso tecnológico, foi uma ferramenta potencial para realização desta atividade. Propiciou um ambiente dinâmico e interativo, no qual a visualização e a interpretação dos conceitos matemáticos utilizados tiveram destaque. Além disso, possibilitou aos estudantes a comprovação de que é possível relacionar a matemática com outras áreas e que os conceitos matemáticos podem ser utilizados para construção de réplicas de obras de arte. Em particular, foi possível fazer com que os estudantes conhecessem um pouco da arte brasileira proporcionada pelo 
artista Geraldo de Barros. Esperamos que este trabalho sirva como contribuição para outros educadores, tanto do ponto de vista da prática de ensino, pois é possível relacionar a arte e a Matemática com recursos tecnológicos, como incentivar a prática reflexiva em sala de aula.

\section{Referências Bibliográficas}

BRASIL. Secretaria de Educação Fundamental. Parâmetros curriculares nacionais: Matemática. MEC /SEF, 1998. 148 p.

BORBA, M. C.; PENTEADO, M. G. Informática e Educação Matemática. 3.ed. Belo Horizonte: Autêntica, 2007.

GRAVINA, Maria Alice...[et al.]. Matemática, Mídias Gigitais e Didática: tripé para a formação de professores. Porto Alegre: Evangraf, 2012.

KAWASAKI, T. F. Tecnologias na sala de Aula de matemática: Resistência e mudanças na Formação continuada de Professores. Belo Horizonte, 2008. Tese. Disponível em:

<http://www.bibliotecadigital.ufmg.br/dspace/bitstream/handle/1843/FAEC84XH59/teresinhakawasakitese.pdf? sequence=1>. Acesso em: 03 de mai. 2015.

MALTEMPI, M. V. Educação Matemática e Tecnologias Digitais: Reflexões sobre prática e formação docente. In: Acta Scientiae. vol.10, São Paulo, 2008.

SOUZA, Joamir Roberto de. Novo olhar matemática. 2 ed. São Paulo: FTD, 2013.

VERTUAN, Rodolfo Eduardo. Um olhar sobre a Modelagem Matemática à luz da Teoria dos Registros de Representação Semiótica. Centro de Ciências Exatas da Universidade Estadual de Londrina. Dissertação de mestrado, Programa de PósGraduação em Ensino de Ciências e Educação Matemática. Universidade Estadual de Londrina: 2007. Acesso em 3de ago. de 2015, disponível em: <http://www.uel.br/pos/mecem/pdf/Dissertacoes/rodolfo_vertuan.pdf>

ZALESKI FILHO, Dierceu. Matemática e Arte. Belo Horizonte: Autêntica, 2013. 